\title{
High bone mass osteogenesis imperfecta
}

INSERM

\section{Source}

INSERM. (1999). Orphanet: an online rare disease and orphan drug data base. High bone mass osteogenesis imperfecta. ORPHA:314029

High bone mass osteogenesis imperfecta is a rare, genetic, primary bone dysplasia disorder characterized by increased bone frag ility, manifesting with mutiple, childhoodonset, vertebral and peripheral fractures, associated with increased bone mass density on radiometric examination. Patients typically present normal or mild short stature and dentinogenesis, hearing, and sclerae are commonly normal. 